\title{
Benefits and Challenges of Peer Observation Among Saudi EFL Female Teachers in Public Schools
}

\author{
Eatedal Alghamdi \\ English Language Institute, King Abdulaziz University \\ Saudi Arabia \\ Turki Alsolami (Corresponding author) \\ English Language Institute, Faculty of Applied Studies \\ King Abdulaziz University, Saudi Arabia \\ E-mail: tgalsolami@kau.edu.sa
}

Received: November 8, 2020 Accepted: December 16, 2020 Published: December 21, 2020

doi:10.5296/ijl.v12i6.17949

URL: https://doi.org/10.5296/ijl.v12i6.17949

\begin{abstract}
This study aims to explore perceptions of the benefits and challenges of peer observation among EFL female teachers in Saudi Arabia working in public schools. A mixed-methods research design was adopted, and two sets of data were collected. The first data was collected using a questionnaire where 231 teachers filled, to elicit teachers' perceptions. The second set of data was collected through a semi-structured interview with six teachers to understand further teachers' perceptions and challenges to peer observation in their contexts. Findings indicate that despite teachers' positive perceptions shown in the question sure results, interviews revealed that teachers are faced with various challenges that hinder the effective implementation of peer observation.
\end{abstract}

Keywords: EFL, Peer observation, Professional development, Questionnaire, Saudi Arabia

\section{Introduction}

Professional development is a practice that takes place in almost all industries, including education. Professional development is an area of research that impacts teaching practices and can take various forms depending on the industry. In education, professional development can broadly refer to the activities that aim to develop and enhance the teaching 
and learning processes in various ways. One of these ways is peer observation of teaching.

Peer observation has been reported to have numerous benefits to the teachers' development on knowledge and teaching skills through collaboration, and to the institutions and improve the quality of teaching that impact students' learning and satisfaction (Agustina et al., 2020). However, despite the reported benefits on the literature on peer observation, a number of studies indicate that it can be intimidating to teachers, particularly if it has not been cautiously introduced and implemented. Peer observation is a common practice in many educational institutions and specialties around the world, including English language teaching (ELT).

The topic of peer observation has been widely researched in many ELT contexts in the world; however, in the Saudi ELT context, particularly public education level, studies are very limited despite the importance and widespread of English teaching in schools and universities. Therefore, this justifies the need for more research in practices of peer observation in Saudi ELT contexts from various stakeholders and, most importantly, the teachers. According to studies conducted in Saudi ELT contexts, implementing peer observation to its full potential is still an issue (Shah, Al Harthi, 2014).. In particular, the influence of peer observation as a contributory factor to the aspect of teacher development in Saudi Arabia has not been explored extensively. Since peer observation can be considered a significant factor in teacher development improvement, there is a need to explore teachers' perceptions and experiences and challenges to peer observation in schools.

\subsection{Significance of the Research}

The studies on peer observation in Saudi ELT teaching at schools are limited, therefore this study significant for many reasons. Firstly, this study aims to gain insights from practicing ELT teachers working in Saudi schools about their benefits and challenges, which can help to understand the situation from large participants from various schools. Secondly, this study can help the researcher design informed workshops or build a framework based on these findings. Thirdly, this study can provide policymakers with findings that can help them to inform and improve current practices of professional development at large and more focused practices on peer observation.

\subsection{Research Questions}

This study about peer observation in EFL teaching in Saudi Arabia attempts to address the following questions:

1. What are the perceptions of EFL female teachers in public schools toward peer observation?

2. What are the benefits and challenges that EFL female teachers perceive towards peer observation?

\section{Literature Review}

\subsection{Peer Observation in ELT}

The importance of peer observation in ELT is as important as any peer observation in other 
subjects. The practice's broad aim is to create an atmosphere of collaboration and reflection among teachers by themselves. In ELT, Richards and Farrell (2005) indicate that peer observation refers to teacher or other observer closely watching and monitoring a language lesson or part of a lesson in order to gain an understanding of some aspect of teaching, learning, or classroom interaction.

Peer observation has various benefits on the educational environments, and a number of researchers proposed models that encompass all these benefits. In ELT, Malderez (2003) identified four purposes for observation, and they are professional development, training, evaluation, and research. Observation for professional development includes observation where an observee makes their own decision about using the observer and their observation. Observation for training includes observation where for the focus of learning is on "skilled practitioner behaviour", and decision on what should be learnt is made by other people other than trainees. Observation for evaluation is where the main purpose is for the observer to make a judgment. Observation for research includes any observations that are carried out for the purpose of creating theories and make positive impact on practices.

Similarly, another widely cited models that can be applied to many professions including ELT was proposed by Gosling (2002). Gosling (2002) identified three different models of peer observation. The first is "evaluation model" which is for senor staff to observe other staff, with a purpose to identify under-performance, confirm probation, appraise, promotion, quality assurance and assessment. The second model is "developmental model" for educational developers to observe practitioners or expert teachers observe other in the department, with a purpose to demonstrate competency, improve teaching and assessment. The third model is "peer review model" which is for teachers to observe each other, with a purpose to engage in a discussion about their teaching and a mutual reflection.

The effectiveness of peer observation of teaching has been documented in a number of studies in in different ELT contexts around the world (Shukri, 2014; Cirocki \& Farrell, 2019; Tzotzou, 2014). Peer observation is viewed as powerful tool to improve the quality of teaching and learning, learning experiences that teachers can benefit from the interactions and feedback in both pre-service and in service. Tzotzou (2014) discussed factors that can contribute to an effective peer observation. The first factor is teachers' awareness of their actions and their willingness to describe and discuss them. Second, feedback is an important aspect of peer observation that involves communicating strength and weakness points to help teachers see the gaps. Third, feedback on one's teaching is an influential trigger for teachers to reflect on their own teaching practices. Lastly, the interaction of various experiences of teachers' knowledge and skills can contribute to professional development.

\subsection{Peer Observation in Saudi Arabian EFL Context}

English Language is the only foreign language taught at Saudi Arabian schools and Universities. English has been recently introduced from the first grade for all public schools. In addition, English is also taught as public universities in the preparatory year. The number of hours varies from schools and universities, where in schools it's around 5 hours a week, and in universities it's between 10-18 hours a week, depending on the academic tracks. Teachers in 
the public schools are all Saudi nationals with a minimum of a BA in English, where at Universities English teachers range from Saudi nationals and non-Saudis coming from English speaking countries and non-English speaking countries. The number of EFL teachers in public school is estimated to be more than 30,000. Those teachers need various support and continuous professional development programs to enhance the teaching and learning process. The forms of professional development range from workshops, seminars, article reading and peer observation, which is the focus of this study.

In the literature of peer observation in EFL in Saudi Arabia A number of studies focused on public education sectors (Alshumaimeri \& Almohaisen, 2017; Alshakihi, 2020; Al-Zahrani \& Rajab, 2017). Most of the studies available were focused more on tertiary education in comparison to studies on public education. In one of the fewest studies in public education, Alshumaimeri and Almohaisen (2017) surveyed 70 male EFL teachers working in schools in Riyadh regarding the most useful professional development activities they are engaged in. The results indicated that the top three activities were discussion a lesson with a supervisor after a class visit (post-lesson discussion), sharing ideas informally with a colleague about teaching, and participating in workshops or seminars. The study also found that $60 \%$ of the teachers were not satisfied with the professional development activities they do in their schools because it integrates little active learning, and also time constraints. The study concluded with suggestions to educational leaders to improve the situation. These suggestions include re-evaluating the current professional development programs, making them more teacher-centred, developing a professional development plan, and conducting studies on teachers' experiences.

In a qualitative study, Alshakihi (2020), explored EFL teachers' perspectives, attitudes, and experiences regarding professional development. Participants reported that their professional development learning was socially negotiated where their knowledge and skills were enhanced through participation, communication, collaboration, and engaging in a mutual concern discussion. As a result, practicing peer observation led to building a better understanding, increased confidence and self-efficacy, and improved teaching practices.

In addition, in-service ELT teachers, pre-service teachers were also investigated by other researchers in the Saudi context. Alamari (2018) conducted a study on EFL pre-service teachers enrolled in a Diploma in teaching to explore teachers' perceptions in field experiences. The study findings indicated that peer observation helped them gained teaching skills and styles by being in a real classroom, got acquainted with students, and expand their opportunity to practice. According to Al-Zahrani and Rajab (2017), the ministry of education has offered EFL teachers in public schools with many pre-service and in-services professional development programs to enhance classrooms' teaching practices. However, professional development in Saudi ELT in public schools still faces many obstacles that impact the overall performance, lessons planning, teaching methodologies, and assessment.

At the tertiary education level, there has been several studies on the issue of EFL teachers in Saudi Arabia professional development in general, and some studies was focused on peer observation (Ahmed et al, 2018; Alshumaimeri \& Almohaisen, 2017; Asmari, 2014; 
Almuhammadi et al., 2020; Shousha,2015; Tawalbeh, 2015). Ahmed et al. (2018) conducted a study at Jeddah University to explore the perceptions of peer observation of EFL teachers using a mixed-method design. Teachers had a positive attitude toward the integration of a peer observation system; however, they expressed some concerns regarding the selection of who they want to observe or be observed with, lack of time to conduct a proper peer observation and lack of training of observers may pose a threat to their jobs security if they were evaluated negatively. In another study at Taif University, Tawalbeh (2015) explored EFL teachers' perception on the existing professional development programs, including peer observation. Findings show that participants had positive attitudes toward their supervisors' observation due to the clear guidelines of pre-observation, during observation, and post-observation, and the "collaborative approach". According to the teachers, the experience was to show teachers their strengths points, appreciate their performance, support teachers, and encourage them to reflect on their teaching practices by creating a dialogue with their observers.

In the same vein, Almuhammadi et al., (2020) conducted a study at The English language institute at King Abdulaziz University on the best professional development that affects teachers' self-efficacy. With reference to peer observation, the study found that peer observation can be a source of EFL teachers' efficacy in verbal persuasion from mentors and observers, which can help improve teachers' performance and emotional status by making them feel more secure and supported. The study found the peer observation positively influenced teaching competencies and practices to better students' learning, created an atmosphere of collegiality, collaboration, and professionalism.

\section{Methodology}

\subsection{Research Design}

The current study aims to explore Saudi EFL teachers' perceptions of the benefits and challenges of peer observation in their respective contexts. Therefore, it requires a better understanding of the issues, which can be done through more than one set of data. This study adopted an explanatory sequential mixed method research design, which consists of two sets of data: quantitative and qualitative (Creswell, 2003). The first data collected is quantitative, followed by a qualitative data collection. The use of this design helps the researcher to explain or elaborate on the quantitative data.

\subsection{Participants and Sampling}

The participants in this study are all EFL teachers currently working in various schools in the educational sector in Saudi Arabia. The participants were female teachers from secondary levels. To attract a large number of participants to take part in the study, in the case of the quantitative data collection, the researcher used the simple random sampling technique. On the other hand, for qualitative data collection, the method of convenient sampling has been used. 


\subsection{Data Collection Instruments}

\subsubsection{Questionnaire}

In order to explore teachers' perceptions of the benefits of peer observation, a small questionnaire was adopted from (Sanif, 2015) study. The questionnaire consists of 12 items with a 5-point Likert scale to show their agreements or disagreement with the questionnaire statement. There was no need to translate the questionnaire into Arabic since all teachers who participated in the study are English teachers.

\subsubsection{Semi-structured Interviews}

In light of the second research question, the researcher developed two interview questions to ask teachers about the benefits of peer observation that were not reported in the questionnaire and another question on the challenges teachers face with peer observation. Six participants showed their willingness to take part in the interview by filling their information in the questionnaire when they were asked about the participation in follow-up interviews.

\subsection{Data Collection Procedures}

For the questionnaire, it was converted into an online version using popular software called survey gizmo. The questionnaire was shared via emails and Telegram or WhatsApp groups for all EFL teachers working in the educational sector in Saudi Arabia.

On the other hand(s), interviews have been conducted online using ZOOM, due to the covid-19, and interviews were recorded for educational purposes.

\subsection{Ethical Consideration}

The educational district office approved this study in Jeddah, and ethical approval was granted to the researcher. As for the study, the questionnaire's online version includes information about the researcher and the study. The researcher clearly mentioned that taking part in the study is on a voluntary basis, and information will be used for research purposes. Prior to the interviews, participants were asked to sign consent. The researcher explained their participation is confidential and anonymous, and all information will be used for research matters.

\subsection{Data Analysis Procedures}

For the quantitative data, SPSS was used to measure all the participants' means on each statement to understand teachers' perceptions. For the interviews, a thematic analysis was performed using Nvivo to unfold the themes mentioned by the participants.

\section{Findings}

\subsection{Finding From the Questionnaire}

As a first step in the analysis of the quantitative data, the reliability test for the questions was calculated using Cronbach's alpha coefficient, as shown in Table 1. 
Table 1. Cronbach's alpha reliability test

\begin{tabular}{ll}
\hline Cronbach's Alpha & N of Items \\
\hline .928 & 12 \\
\hline
\end{tabular}

The above table reveals that the value of Cronbach's Alpha is 0.928, which is more than 0.7, due to which the quantitative questionnaire of this study can be considered as reliable.

As for the questionnaire, teachers were asked to indicate their level of agreement or disagreement with each statement describing the potential benefits of peer observation. Means scores for each benefit is presented in the table below.

Table 2. Descriptive statistics calculation

\begin{tabular}{|c|c|c|}
\hline Questionnaire items & $\mathrm{N}$ & Mean \\
\hline 1. Peer observation enabled me to learn new skills & 231 & 4.18 \\
\hline $\begin{array}{l}\text { 2. Peer observation gave me the opportunity to gain valuable insights } \\
\text { my teaching }\end{array}$ & $\mathrm{n}_{231}$ & 4.14 \\
\hline 3. Peer observation helped to change my teaching methods/ routines & 231 & 4.13 \\
\hline $\begin{array}{l}\text { 4. Through peer observation I become more willing to share and leat } \\
\text { from colleagues }\end{array}$ & 231 & 4.12 \\
\hline 5. Peer observation facilitated the use of a wider range of techniques & 231 & 4.11 \\
\hline $\begin{array}{l}\text { 6. Peer observation made me more reflective and aware about my ow } \\
\text { teaching }\end{array}$ & $\mathrm{n}_{231}$ & 4.10 \\
\hline 7. Peer observation helped to improve the atmosphere of cooperating & 231 & 4.09 \\
\hline 8. $\quad$ Peer observation helped me accept feedbacks from colleagues & 231 & 4.07 \\
\hline 9. $\quad$ Peer observation made me gain more confidence & 231 & 4.03 \\
\hline 10. Peer observation created better communication among teachers. & 231 & 3.97 \\
\hline $\begin{array}{l}\text { 11. Peer observation activity resulted in increased professionalism in } \mathrm{m} \\
\text { attitude toward teaching }\end{array}$ & 231 & 3.96 \\
\hline 12. As a teacher, I understand the purposes of peer observation & 231 & 3.94 \\
\hline
\end{tabular}

As can be noticed from the results above, teachers show a high level of agreement with most of the benefits mentioned in the questionnaire, which imply that teacher perceives that peer observation is important in their practices. Individually, learning new skills was rated as the highest benefits reported with a mean of 4.18 , followed by gaining a valuable insight into their teaching with a mean of 4.14 . Then they were willing to share and learn with colleagues with a mean of 4.13. As can be seen from the table, the rest of the items were closely in terms of means. The lowest benefits understood the purpose of peer observation with a mean of 3.94. Before that, the increase of professionalism 3.96, which may imply dissatisfaction with peer observation from teachers? 


\subsection{Findings From Semi-structured Interviews}

Six EFL practicing teachers working at various levels in public schools for many years were interviewed. Teachers were asked about the benefits and challenges regarding peer observation in their teaching contexts. Interviews were conducted online due to Covid-19, and each interview lasts for 10 minutes. Each participant signed a consent form that declares their anonymity and confidentiality of their identity. Teachers shared their answers to the questions regarding their experiences of the benefits and challenges they face when implementing peer observation.

\subsubsection{Benefits of Peer Observation}

Teachers were asked about how they perceive the benefits of peer observation based on their experiences. One of the benefits that were mentioned by a number of participants that peer observation is a good way for teachers to learn and share experiences, which are very apparent in the following quotes:

"If you mean when someone attends my class the benefit, they can attend my class and write down all the points if they have then we can sit down together and we listen and we can share and talk about her experience we can hear the advantages and disadvantages of the ways or the strategies or any way of teaching in the class" (participants 1)

“As teachers we always learn from each other's. Sharing experience works as a shortcut for new teachers. Starting from where the others ends is really smart. It's like using more than one brain which result in big effective ideas". (Participant 4).

In my opinion, these sometimes peer observation builds a strong relationship between teachers and also it improves teaching practices, give more ideas about anything in a way that inspires you when attending to your colleague to somehow to adapt new and creative ideas (Participant 5)

Another benefit that was reported by other teachers was that peer observation is very useful for teachers' needs to improve their teaching skills through learning from observing others or being observed. The following quotes were mentioned by two teachers:

“...............to engage a professional learning to improve teaching enhance students' learning through reflective practice demonstrate leadership by observing and supporting other teachers celebrate excellent teachers through the establishment of peer observers gather evidence of teaching quality to support career progress." (Participant 3 )

the benefits are that someone else actually sees the weak points or your weak points while introducing the lesson what you should improve, where you should take longer time to introduce a step what you should exactly in another point (Participant 4)

I myself attend others' classes and do some peer observation for this reason because I wanted to see how others deal with students how do they do classroom management how do they praise students how do they introduce the lesson how to sum up the ideas at the end so while being observed (Participant 6) 
These benefits mentioned by the teachers in the interview correspond to some of the statements mentioned in the questionnaire with high means. The highest item is related to learning new skills and item 4 in the questionnaire about sharing and learning from colleagues.

\subsubsection{Challenges of Peer Observation}

The second open-ended question was related to the challenges teachers encountered when implementing peer observation. Many of the participants shared their concerns about those challenges. One of the many challenges reported among teachers was the time limitation. This challenge was highlighted by a number of teachers who reported that due to time constraints and the high number of teaching hours and paperwork they are involved in, peer observation could not be implemented effectively, as shown in the following quotes:

"you know the challenges is the time is the most the main or the most dominant obstacle is the time you know that most of the English teachers here are having 20 classes a week so in each class you have to do a lot of things and to cover all the 4 skills and you know the number of students in the classroom so it's not that easy to welcome someone in your class once or twice a week" (Participant 1).

"My colleagues and I have 24 classes per week. No time to do something like that. We are stressed with classes" (Participant 2).

“...having many periods and many syllabuses that you don't have time and desire to imply it" (Participant 5).

Another challenge that was reported by other teachers was the acceptance of being observed by other teachers. This, they felt was due to the lack of importance of Peer observation or to the rejection of new ideas or being criticized by others.

"I'm ready to accept anything but for the post peer observation discussion I prefer either if I'm the one who is observing others, or I'm being observed I'd rather having it privately for any reason because I don't like to be criticized in front of others, they haven't attended the class" (Participant 3)

"The fear of being criticized just having them watch me is what increases my nervous state. I find that criticizing is part of our job for 20 years I've been criticized by my students all the time." (Participant 1)

"Somehow actually because the times that I have been criticized or peer observed they didn't participate of actually building me they find the mistakes I think without giving me an actual feedback of what I can do or how I can I improve it." (Participant 5)

Another challenge that was reported by two of the participants was lack of clear guidelines while conducing peer observation or post observation, as shown in the following quotes:

"Challenges actually comes from the person who is observing you because you don't know what do they expect so you just try to work on the guidelines they gave you or everybody 
knows and you work with them. But you think you are doing fine until someone observes you and finds the weak points" (Participant 2)

"..........according to the directions are given from the supervisors the challenge is to change or look for a way to change because usually, they don't tell you how to change they just tell you and your job is to find a way of changing and improving." (Participant 4).

\section{Discussion}

This study aims to explore the perception of the benefits and challenges of peer observation among EFL teachers in the public education sector the Saudi context. To answer the researched questions of this study, a mixed-method was adopted, and findings were triangulated to gain a better perspective on the researched issue. Two hundred thirty-one female Saudi EFL teachers from various public schools in Jeddah filled out the online questionnaire. Six teachers expressed their willingness to take part in an interview regarding peer observation practices in their respective schools.

The results indicated the agreement amongst the majority of the teacher participants who acknowledged the importance of peer observation. Some even considered it as a must in the process of feedback and reflection on the individual teacher's performance. The quantitative results were all positive about the benefits of that peer observation offered. Among the various items in the questionnaire, EFL teachers in the study highly regard peer observation, in particular, as a tool to learn new teaching skills, gain more knowledge that helps them to improve their teaching styles. These findings were also confirmed in the interviews with the teachers. These findings were reported in previous studies internationally and in Saudi EFL contexts (Ahmed et al., 2018; Alamari, 2018; Alshakihi, 2020; Almuhammadi et al., 2020). In addition, sharing experiences and feedback with other teachers was reported by a number of teachers in both sets of data. According to some participants in this study, sharing experiences and positive feedback with observers made increase their confidence and satisfaction, which was also found in previous studies (Agustina et al., 2020, Almuhammadi et al., 2020), where teachers, in addition to being confident and satisfied, they were felt secured and supported.

Regarding the challenges EFL teachers face when implementing peer observation, teachers in this study reported that time limitation and negative perceptions are the two most challenges. Regarding time, several teachers complain about a lack of time to effectively implement peer observation due to hours of teaching loads in addition to other administrative duties. This can lead to the reversed intended results aimed from peer observation. In other words, teachers who have busy teaching schedules and large class sizes, may find it difficult to dedicate time towards peer observation and the feedback they may give or receive from their peers. It can add more burden and stress on the teachers and thus, may lead to negative results. Findings in this study are in line with previous results of studies conducted in Saudi ELT contexts (Ahmed et al., 2018; Alshumaimeri \& Almohaisen, 2017, Shukri, 2014, Shousha, 2015). If we are to maximize the benefits intended from peer observation, we need to consider all the affecting factors and plan well ahead of the process. This will certainly yield positive responses from the teachers as well as lead to successful outcomes intended from the peer observation process. 


\section{Mll Macrothink}

International Journal of Linguistics

ISSN 1948-5425

2020, Vol. 12, No. 6

The second challenge that was reported by other teachers the acceptance of being observed by other teachers. Participants in this study reported a number of reasons for rejecting of peer observation, such as fear of being sensitive to evaluation by an observer or provided with negative feedback from observers. This challenge was reported in a number of previous studies (Ahmed et al., 2018; Shukri, 2014). Shukri (2014), stresses the observer's role for a successful peer observation by having a high standard of conduct and ethics, patient and understanding, and provide positive feedback more on the strength points more on weakness. Shousha (2015) found that teachers lack of training skills, and giving feedback was a challenge resulting in negative feedback.

Another minor challenge reported in the study was the lack of clear guidelines and expectations, which was also a challenge of peer observation in previous studies (Sanif, 2015; Shukri, 2014). Having a clear instructions and framework can make the process of peer observation clear for observer and observe and ease the tension.

In Summary, the findings of this study are in line with previously established perceptions of peer observation on the reported benefits and the challenges reported in previous studies in international and Saudi ELT contexts. Findings of both data indicate that teachers in this study perceive peer observation as a positive professional and learning experience which requires careful implementation and consideration as it associated with teachers' personality and sometimes job security, in addition to time. Studies provide a recommendation to improve the quality of peer observation in their contexts, such as providing workshops and article to increase awareness of the importance of peer observation and its effectiveness.

\section{Conclusion}

Peer observation is one form of the many that impact the teachers' knowledge and skills of teaching and aim to improve the quality of teaching for better students' learning. Peer observation is an important professional development activity that should be nurtured and promoted among teachers to provide an opportunity for experienced teachers and novice teachers to share knowledge and experiences to enhance each other skills. Challenges to peer observation such as time or others should be eliminated by either the school of the educational district.

\section{References}

Agustina, N. Q., Azima, N., \& Januardie, E. (2020). Teachers' perception and the implementation of peer observation at the language center in a private university. Journal of Foreign Language Teaching and Learning, 5(1), 40-56.

Ahmed, E., Nordin, Z. S., Shah, S. R., \& Channa, M. A. (2018). Peer observation: A professional learning tool for English language teachers in an EFL institute. World Journal of Education, 8(2), 73. https://doi.org/10.5430/wje.v8n2p73

Alamri, H. R. (2018). Challenges in practicum: views and perceptions of EFL pre-service teachers towards field experience skills in real classrooms. Arab World English Journal, 9(1), 146-162. https://doi.org/10.31235/osf.io/vnhsj 
Almuhammadi, K. H., Assalahi, H. M., \& Madini, A. A. (2020). Saudi female EFL instructors' perceptions of the effects of professional development on their self-efficacy. English Language Teaching, 13(10), 74. https://doi.org/10.5539/elt.v13n10p74

Alshaikhi, H. I. (2020). Self-directed teacher professional development in Saudi Arabia: EFL teachers' perceptions. Theory and Practice in Language Studies, 10(11), 1359. https://doi.org/10.17507/tpls.1011.03

Alshumaimeri, Y. A., \& Almohaisen, F. M. (2017). Saudi EFL teachers' perceptions of professional development activities. Journal of Education \& Social Policy, 7(1), 185-193.

Al-Zahrani, N. O., \& Rajab, H. (2017). Attitudes and perceptions of Saudi EFL teachers in implementing Kingdom Of Saudi Arabia's vision 2030. International Journal of English Language Education, 5(1), 83. https://doi.org/10.5296/ijele.v5i1.10733

Asmari, A. A. (2014). Teachers' perceptions about the use of mother tongue in Saudi EFL University classrooms: A gender-line investigation. Theory and Practice in Language Studies, 4(10). https://doi.org/10.4304/tpls.4.10.2066-2075

Cirocki, A., \& Farrell, T. S. (2019). Professional development of secondary school EFL teachers: Voices from Indonesia. System, 10211. https://doi.org/10.1016/j.system.2019.102111

Creswell, J. W. (2003). Research design: Qualitative, quantitative, and mixed methods approaches. SAGE.

Gosling, D. (2002). Models of peer observation of teaching. Generic Centre: Learning and Teaching Support Network, 8(10), 1-6.

Malderez, A. (2003). Observation. ELT Journal, 57(2), 179-181. https://doi.org/10.1093/elt/57.2.179

Richards, J., \& Farrell, T. (2005). Peer observation. In Professional development for language teachers: strategies for teacher learning (pp. 85-97). Cambridge University Press.

Sanif, S. (2015). Implementation of peer observation of teaching in ELT tertiary education system in Malaysia: a social-constructionism view. Unpublished doctoral dissertation. University of Exeter.

Shah, S., \& Alharthi, K. (2014). TESOL classroom observations: a boon or a bane? An exploratory study at a Saudi Arabian University. Theory and Practice in Language Studies, 4(8), 1593-1602.

Shousha, A. I. (2015). Peer observation of Teaching and Professional Development: Teachers' Perspectives at the English Language Institute, King Abdulaziz University. Arab World English Journal, 6(2), 131-143.

Shukri, N. (2014). Exploring female teachers' perceptions towards teacher observation: issues and challenges in the Arab context. Arab World English Journal, 153-166. 


\section{Macrothink}

International Journal of Linguistics

ISSN 1948-5425 2020, Vol. 12, No. 6

Tawalbeh, T. I. (2015). Instructors' perceived effectiveness of current professional development programs at Taif University English language center. English Language Teaching, 8(11), 117. https://doi.org/10.5539/elt.v8n11p107

Tzotzou, M. D. (2014). Designing a set of procedures for the conduct of peer observation in the EFL classroom: A collaborative training model towards teacher development. Multilingual Academic Journal of Education and Social Sciences, 2(2), 19-33. https://doi.org/10.6007/majess/v2-i2/1387

\section{Copyrights}

Copyright for this article is retained by the author(s), with first publication rights granted to the journal.

This is an open-access article distributed under the terms and conditions of the Creative Commons Attribution license (http://creativecommons.org/licenses/by/4.0/) 